\title{
Influence of tropospheric temperature gradient on the boreal wintertime precipitation over East Asia
}

\author{
Bakshi Hardeep Vaid* and X. San Liang
}

School of Marine Sciences, Nanjing University of Information Science and Technology (NUIST), Nanjing, China

\author{
Article history: \\ Received 13 June 2018 \\ Revised 27 September 2018 \\ Accepted 24 October 2018 \\ Keywords: \\ TT gradient, Precipitation, Thermal \\ wind, Boreal winter, ENSO \\ Citation: \\ Vaid, B. H. and X. S. Liang, 2019: \\ Influence of tropospheric temperature \\ gradient on the boreal wintertime \\ precipitation over East Asia. Terr. \\ Atmos. Ocean. Sci., 30, 161-170, doi: \\ 10.3319/TAO.2018.10.24.01
}

\begin{abstract}
Recently it has been found that the summertime tropospheric temperature gradient (hereafter TT gradient) over East Asia provides a natural characterization of the local climate variability, particularly, the precipitation variability, and can help forecast the onset of summer monsoon. In this study we extend the study to the winter months, using the National Center for Environmental Prediction (NCEP) - DOE AMIP 2 reanalysis daily datasets. It is shown that the TT gradient during the El Niño years is significantly smaller than that during the La Niña years, and the difference in TT variation in the two ENSO phases leads to a distinctly different pattern of variability of precipitation over East Asia. The corresponding variabilities of circulation and moisture transport are in agreement with the observation, which are further substantiated in a causal inference using the traditional regression analysis and a newly developed causality analysis technique with time series.
\end{abstract}

\section{INTRODUCTION}

The boreal winter monsoon is one of the important climate systems; its anomalous variations can lead to disasters, such as anomalous precipitation, over East Asia, and, consequently, plays a significant role in the economy of region (Huang et al. 2007; Zhou et al. 2009). Numerous previous studies (e.g., Jhun and Lee 2004; Wang et al. 2009; Ha et al. 2012) have reported that the interannual variability of the boreal winter monsoon variability over East Asia is distinct. It is closely related to the large-scale circulations such as the Siberian high, Aleutian low, East Asian jet, and Arctic oscillation (Thompson and Wallace 1998); it is also observed to be significantly affected by El Niño-Southern Oscillation (ENSO) (Wu et al. 2003; Zhou and Wu 2010). However, it remains unclear whether there is any linkage between the tropospheric temperature (hereafter TT) and winter precipitation over East Asia, especially during the ENSO periods. To our best knowledge, the TT variations and its associated impacts in the boreal winter months, i.e., December, January, and February (hereafter DJF), which make the mature

\footnotetext{
* Corresponding author

E-mail:bakshi32@gmail.com
}

phase of ENSO, have not been fully recognized.

Recently, many studies have highlighted the importance of the TT variation and its role in the precipitation variability over East Asia the most active area of the climate system. They are however focused mostly on the seasonal transition and summer monsoon period, including Schneider and Lindzen (1977), Gill (1980), Webster et al. (1998), Rodwell and Hoskins (1996), Wu (2005), Emanuel (2010), Vecchi et al. (2013), and Vaid and Liang $(2015,2018)$, to name a few. It is found that the deep tropospheric heating cannot be elucidated by the classical land-ocean contrast model involving surface temperature gradient forces (Schneider and Lindzen 1977), as the model can only explain shallow circulations. Webster et al. (1998) observed that the deep Asian monsoon circulation is a manifestation of the meridional gradient of the deep tropospheric heat and may be efficaciously represented by the meridional gradient of the TT. In response to such a heat source (Gill 1980; Rodwell and Hoskins 1996), a large scale cyclonic circulation is generated above the planetary boundary layer (PBL). Besides, it is shown (Wu 2005) that the TT decreases over East Asia and the African monsoon region weaken the Indian summer monsoon circulation during the mid-1960s, and TT has been 
evidenced to influence the tropical storm activities through changing the storm intensity (Emanuel 2010; Vecchi et al. 2013). Recently, the role of TT gradient in driving the south and East Asian summer monsoon has been identified (Vaid and Liang 2015), and, moreover, the gradient during the seasonal transition period is found to undergo an abrupt change late in the 1990s (Vaid and Liang 2018). In this study, we will continue our previous research along the line (Vaid and Liang 2015,2018 ) but with a focus on the boreal wintertime (namely the DJF period) in the ENSO years. In other words, this study is intended to present the distinct spatiotemporal pattern of TT variation over East Asia, which has never been revealed before, during the boreal winter period, particularly during the ENSO winters. The remaining part of this paper is organized as follows. In section 2 , we introduce the data and analysis methods. The TT gradient pattern and its associated relationship with anomalous atmospheric circulation in El Niño and La Niña years are revealed in section 3. A summary of the study is given in the last section.

\section{DATA AND METHODOLOGY}

We derive the horizontal wind fields, air temperature and relative humidity (Kanamitsu et al. 2002) from the National Center for Environmental Prediction (NCEP) - DOE AMIP 2 reanalysis daily datasets, which are provided by the NOAA/OAR/ESRL PSD, Boulder, Colorado, USA (http:// www.esrl.noaa.gov/psd/). The precipitation data is from Asian Precipitation - Highly-Resolved Observational Data Integration Towards Evaluation (APHRODITE's) of Water Resources (http://www.chikyu.ac.jp/precip/english/products.html) (Yatagai et al. 2012), and the SST anomalies are derived from the National Oceanic and Atmospheric Administration (NOAA) Optimum Interpolation (OI) sea surface temperature (SST) V2 (OISSTV2) (Reynolds et al. 2002) (https://www.esrl.noaa.gov/psd/).

The ENSO events during the boreal winter of East Asia (DJF) for the period 1982 - 2014 are identified using the SST anomaly-based Niño-3 index (area-averaged SST anomaly over $150-90^{\circ} \mathrm{W}, 5^{\circ} \mathrm{N}-5^{\circ} \mathrm{S}$ ). The index is normalized by its standard deviation (Fig. 1), and the years with a standard deviation greater than 0.8 are considered as an event year in this study. Based on the Niño-3 DJF index for the period $1982-2014$ (Fig. 1), the boreal winters in the four years, DJF 1982/83, 1986/87, 1991/92, and 1997/98 are identified as El Niño winters, and five other winters, i.e., DJF 1984/85, 1988/89, 1999/00, 2007/08, and 2010/11 are La Niña winters. The so-identified El Niño years and La Niña years are consistent with those in previous studies (e.g., Ratnam et al. 2014).

Further, to understand the causal mechanism associated with TT variation during the El Niño and La Niña events, moisture transport has been examined; particularly, the total horizontal mean transport components (zonal and meridional) of water vapour have been calculated using the following formula:

$Q_{\lambda}=\frac{1}{g} \int_{P_{b}}^{P_{t}} r h u d p$

$Q_{\phi}=\frac{1}{g} \int_{P_{b}}^{P_{t}} r h v d p$

where $Q_{\lambda}$ is the zonal component, and $Q_{\phi}$ is the meridional component of the vertically integrated total mean vapor flux, $r h$ (relative humidity) is the ratio of the partial pressure to the equilibrium vapor pressure of water vapor, $(u, v)$ is the velocity vector, $g$ is the acceleration due to gravity, and $P_{b}$ and $P_{t}$ are the pressures at the bottom $(850 \mathrm{mb})$ and top $(200 \mathrm{mb})$ levels of the integration volume, respectively. Based on this the moisture flux across a section can be computed:

$F_{v}=\frac{1}{g} \int_{P_{b}}^{P_{t}} \int_{0}^{L} r h v_{n} d p d l$

where $v_{n}$ is the wind component normal to the horizontal section, and $L$ is the length of the section.

Besides, to quantitatively examine the measurable impact of the TT variation on the precipitation over East Asia during El Niño and La Niña events, we use the traditional regression analysis technique and a newly developed theory and methodology for identifying the causality between time series (Liang 2014, 2015, 2016). We adapt that methodology for the purpose of this study by introducing a "composite causality analysis". The details are referred to Appendix A.

\section{RESULTS}

We take average of the TT between $1000-400 \mathrm{mb}$ and draw the composite TT variations during El Niño and La Niña events (Figs. 2a and b, respectively). Figure 2c shows their difference, i.e., the TT during the El Niño events minus that during the La Niña events, along with statistical significance (regions enclosed in black contours are significantly different from zero at a $99 \%$ level). From the figure we can distinguish two regions. Over the region $72-120^{\circ} \mathrm{E}, 40-$ $57^{\circ} \mathrm{N}$ (hereafter region I), the troposphere seems to be relatively warmer during El Niño than during La Niña events, whereas over the region $72-120^{\circ} \mathrm{E}, 16-30^{\circ} \mathrm{N}$ (hereafter region II) the TT is cooler during the El Niño events than during the La Niña events. Mostly the warming and cooling of the TT are confined to these two regions in the two ENSO phases. The difference (Fig. 2c) reveals that there exists a sharp gradient in TT over East Asia, with one pole over region I, another over region II. We hence define an index, called TT gradient, as the difference between the TTs over 


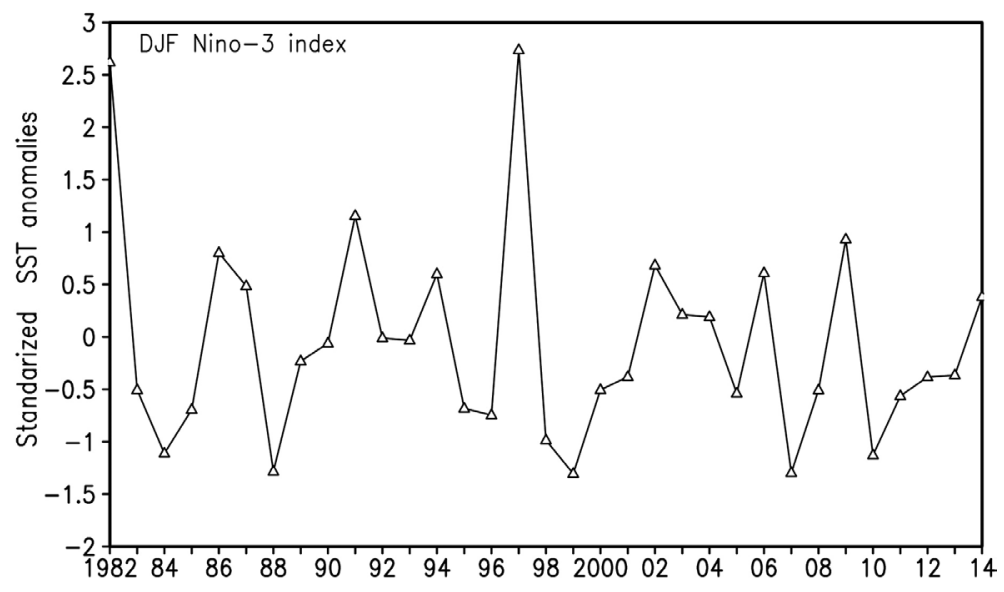

Fig. 1. Standardized DJF SST anomalies based on the Niño-3 index.

(a) DJF AVE TT (EI Nino) $=0$

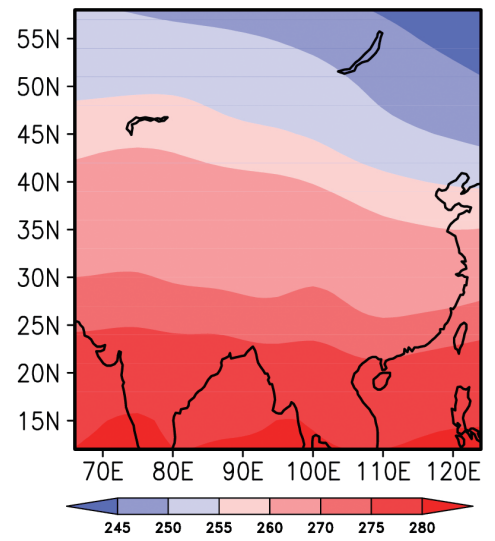

(b) DJF AVE TT (La Nina) $=b$

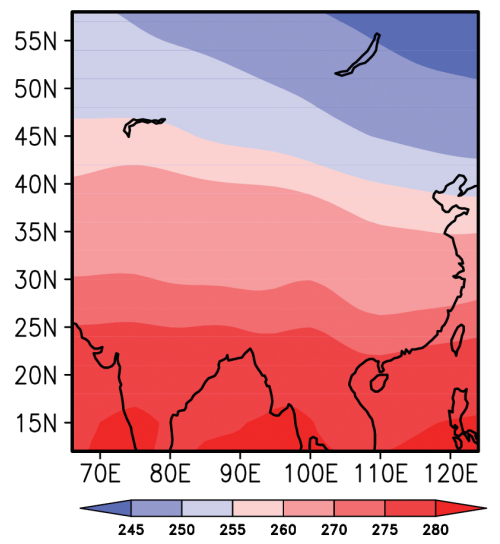

(c) DIFFERENCES $(a-b)$

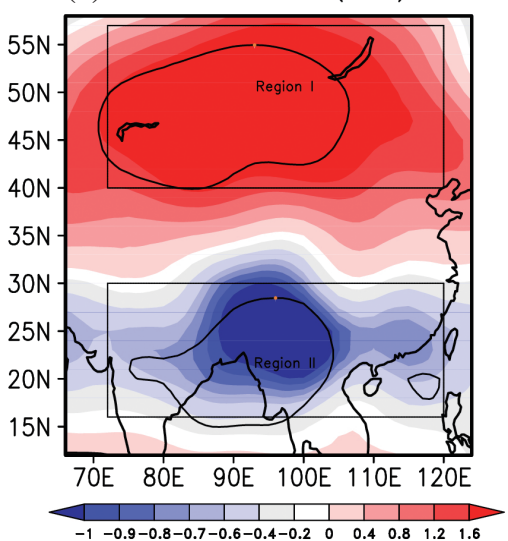

Fig. 2. DJF TT (in K) during (a) El Niño events and (b) during La Niña events. (c) The difference between (a) and (b), i.e., (a) - (b). The regions enclosed in black contours are significantly different from zero at a $99 \%$ level.

these regions. As from previous studies the TT variations play a vital role in precipitation variability over south and East Asia (Vaid and Liang 2015, 2018), we speculate that the contrast in TT distribution during El Niño and La Niña events may cause a measurable impact on the precipitation over East Asia, which we explore henceforth.

In order to see how the TT gradient varies with time, in Fig. 3 it is plotted for the El Niño events and La Niña events, respectively. Evidently, during the El Niño years, TT gradient is observed to be significantly smaller than that during the La Niña years (Fig. 3c). However, the oscillation is more pronounced in El Niño years, Niño (in El Niño winters: variance 2.90; standard deviation 1.70; in La Niña winters: variance 2.04; standard deviation 1.43).

By the thermal wind relation, such a gradient will play an important role in driving the circulation (e.g., Webster 1987; Holton 2004; He et al. 2007). This motivates us to see what a circulation pattern the TT variation would lead to during El Niño and La Niña events. We draw in Figs. $4 \mathrm{a}$ and $\mathrm{b}$ wind vectors at $200 \mathrm{mb}$ for El Niño and La Niña events, respectively. The wintertime subtropical jet is clearly seen; it is like its DJF climatology (cf., the Fig. 2.15 of Neelin 2011) but with different intensity. Notice that even modest changes in jet stream location, intensity or altitude can impact stratospheretroposphere exchange (Wei 1987), circulation regime shift (Ruti et al. 2006), etc., and hence lead to severe weather (Nakamura 1992). Given the facts that the jet stream's sensitivity to the distribution of air temperature (e.g., Palmén 1948) and the evolving thermal structure of the troposphere, also plotted are the resulting difference between wind vectors at $200 \mathrm{mb}$ for the two ENSO phases (i.e., EL Niño events minus La Niña events; Fig. 4c and La Niña events minus EL Niño events; Fig. 4d). From it the TT variation during the El Niño events seems to be associated with the distinctive circulation. The closed loop circulation structures are clearly seen over regions I and II. A conspicuous feature is an anticyclonic (cyclonic) circulation over region I (region II) during the El Niño (La Niña) events (Figs. 4c and d). Just 
like the wind vectors at $200 \mathrm{mb}$, we also show the wind shear (200 - $850 \mathrm{mb}$ ) during the El Niño and La Niña events, and, clearly, they also reveal similar structures (Figs. 4e - h). In order to examine the water vapor budgets and hydrology cycles, also computed is the vertically integrated moisture transports during the El Niño and La Niña events, using the formulas in section 2 (Figs. $4 \mathrm{i}-1$ ). Clearly the moisture transport distribution appears to be consistent with that of wind vectors. As moisture is a basic element in the monsoon precipitation variability, we go ahead to examine the moisture fluxes across a typical meridional wall and a zonal wall during both El Niño and La Niña events.

The longitude and latitude for the meridional and zonal sections are chosen on the basis of the unveiled tropospheric temperature gradient (Fig. 1c) in the midst of the two dipolar regions. The former is set to be at $90^{\circ} \mathrm{E}$ from $31-39^{\circ} \mathrm{N}$, while the latter is at $35^{\circ} \mathrm{N}$ from $80-100^{\circ} \mathrm{E}$. First look at the meridional wall. The vertical integration is between the levels 850 - $200 \mathrm{mb}$ and the resulting fluxes are plotted in Fig. 5. During the El Niño periods, the series has a variance of 73.98, or a standard deviation of 8.60 (Fig. 5a), while during the La Niña periods, the variance is 56.28 (or standard deviation: 7.50) (Fig. 5b). The positive values of the moisture flux across the meridional wall mean that the moisture transport over the region is always eastward. The difference between Figs. 5a and b is also plotted, as shown in Fig. 5c. Interestingly, the TT gradient is in accordance to the flux; particularly, smaller/larger TT gradients during El Niño/La Niña events correspond to small/larger moisture transports between the two regions, namely, regions I and II.

For the flux across the zonal wall at $35^{\circ} \mathrm{N}$ from $80-$ $100^{\circ} \mathrm{E}$, we repeat the same computations as above. Likewise, the resulting series for the two ENSO phases have different variances: the meridional moisture flux during El Niño has a variance of 31.14, whereas that during La Niña has a variance of 26.16. From Figs. 5d, e, and f, in El Niño years, a substantial reduction in moisture flux is clearly seen, echoing the reduction in temperature gradient during El Niño events (refer Fig. 3). In other words, the TT gradient variation has indeed caused the reduction in moisture transport between regions I and II.

The above can be understood with the aid of thermal wind relation. The geostrophic velocity difference between the two pressure levels 1000 and $400 \mathrm{mb}$ is

$-\frac{R}{f} \nabla_{p}\langle T\rangle \ln \left(\frac{P_{0}}{P_{1}}\right)$

where $\langle T\rangle$ is the temperature between two pressure levels, $R$ the universal gas constant, $f$ the Coriolis parameter, and $\nabla_{p}$ the gradient operator on the pressure surface. This formula says that, in the Northern Hemisphere, if we face downstream, the warm air is on our right hand side. This

(a) DJF TT gradient during El Nino

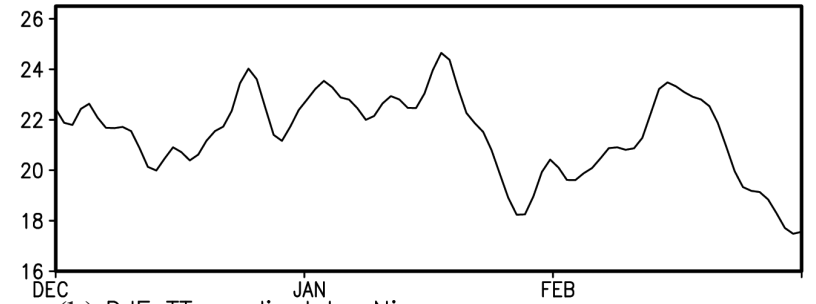

(b) DJF TT gradient La Nina

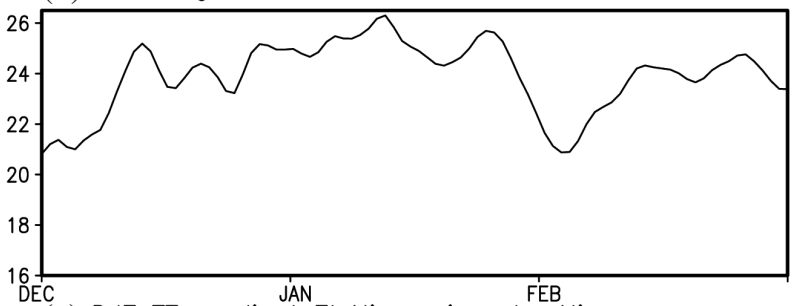

(c) DJF TT gradient El Nino minus La Nina

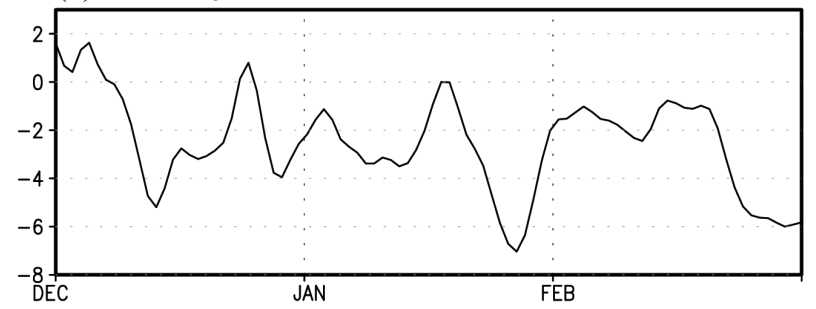

Fig. 3. DJF TT gradient during (a) El Niño events and (b) La Niño events. (c) Difference between (a) and (b). 


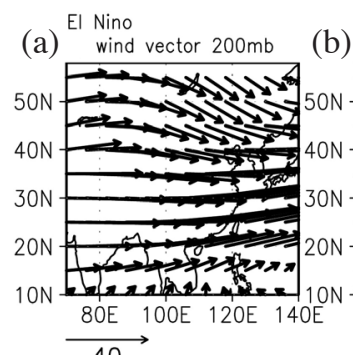

(b) La Nina

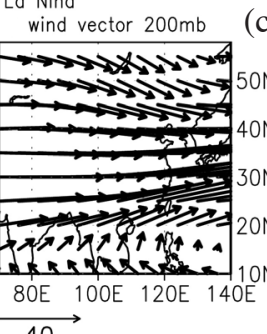

(c) El Nino minus La Nina

(d) La Nina minus El Nino

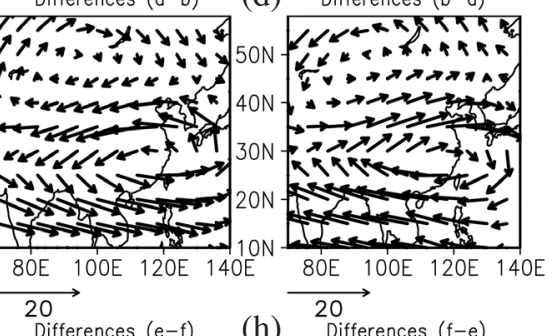

(e) wind vector shear

(f) wind vector shear

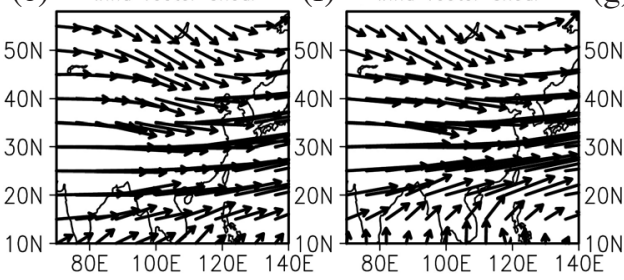

g) Differences $(e-f)$

(h) Differences $(f-e)$

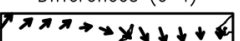

(h) Differences $(t-e)$

$x \pi x \rightarrow x y+t+\infty$

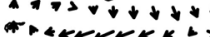

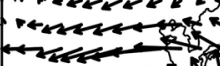

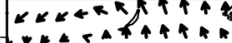
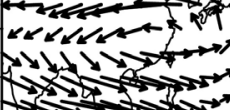

$40 \mathrm{~N}$

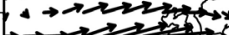

$30 \mathrm{n}$

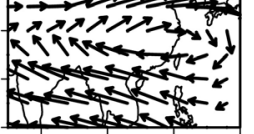

$10 \mathrm{~N} \frac{1}{80 \mathrm{E}} 100 \mathrm{E}$ 120E $140 \mathrm{E}$ 80E $100 \mathrm{E}$ 120E $140 \mathrm{E}$

(i) $\stackrel{40}{\text { Moist. flux vector }}$

(j) $\stackrel{40}{\text { Moist. flux vector }}$

$80 \mathrm{E} 100 \mathrm{E} 120 \mathrm{E}$ 140E

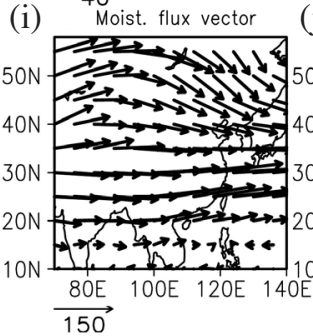

(k) $\stackrel{20}{\text { Differences }(\mathrm{i}-\mathrm{j})}$

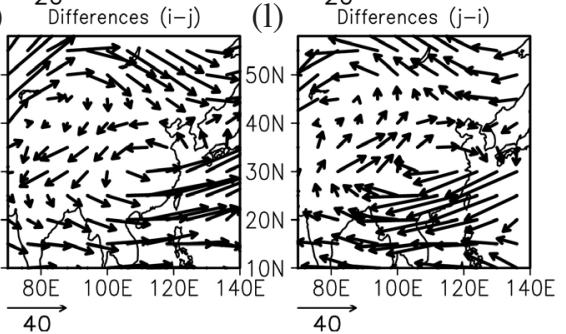

Fig. 4. Wind vector (in $\mathrm{m} \mathrm{s}^{-1}$ ) at $200 \mathrm{mb}$ (a) during El Niño events and (b) during La Niña events. (c) is (a) - (b), (d) is (b) - (a), (e) to (h) is same as (a) to (d) but for wind vector shear (200 - $850 \mathrm{mb}$ ). (i) to (1) is same as (a) to (d) but for vertically integrated moisture flux vector between 850 to $200 \mathrm{mb}$ level.

Zonal Transport during DJF for lon $=90 \mathrm{E}$;lat31 to $39 \mathrm{~N}$; levels 850 to $200 \mathrm{mb}$
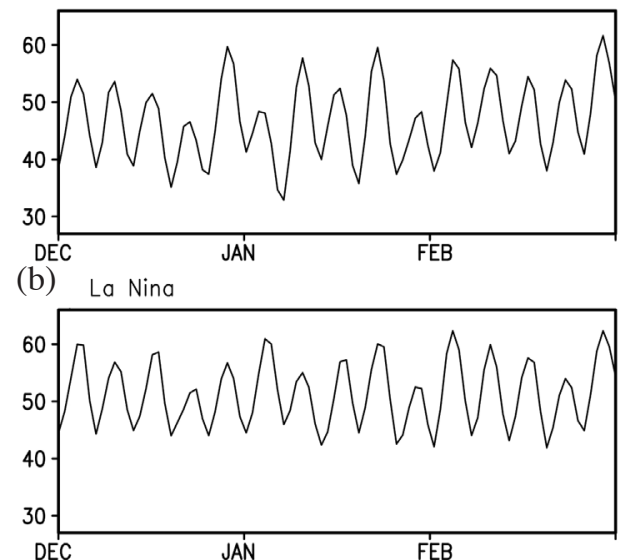

(c) El Nino minus La Nina

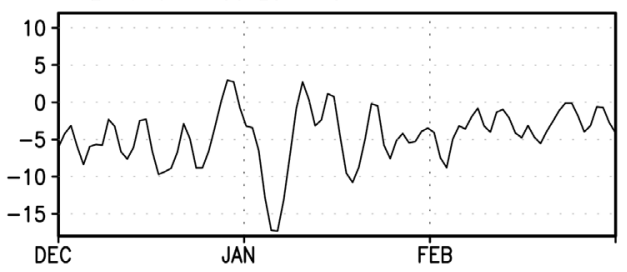

Meridonal Transport during DJF for lon $=35 \mathrm{~N}$; lat 80 to $100 \mathrm{E}$;levels 850 to $200 \mathrm{mb}$ (d) El Nino
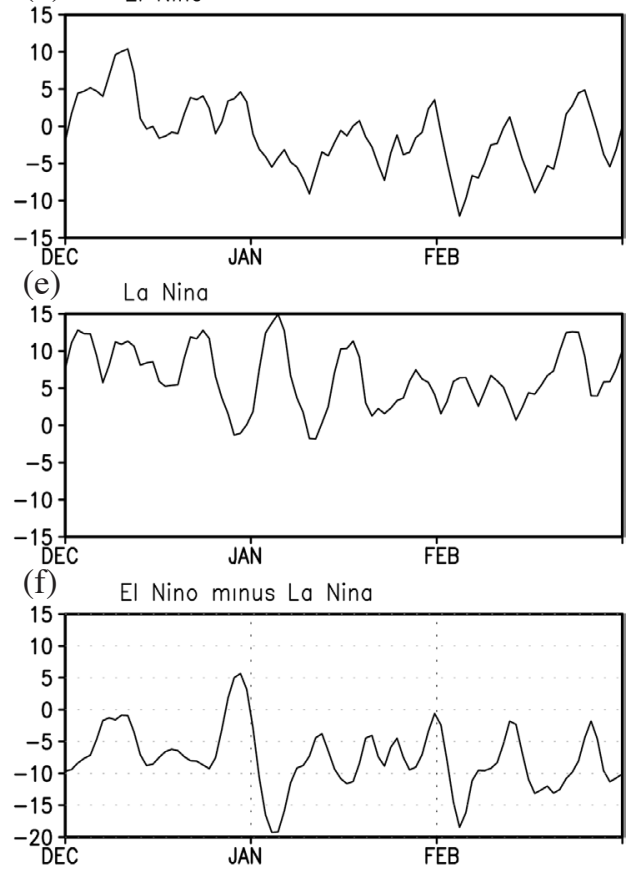

Fig. 5. (a), (b) are the moisture fluxes $\left(\times 10^{8} \mathrm{rh} \mathrm{s}^{-1}\right)$ across the meridional wall (at $90^{\circ} \mathrm{E}$, from $\left.31-39^{\circ} \mathrm{N}\right)$ for El Niño and La Niña events, respectively; (c) is the difference (a) - (b). (d), (e) are the moisture fluxes across the zonal wall (at $35^{\circ} \mathrm{N}$, from $80-100^{\circ} \mathrm{E}$ ) for El Niño and La Niña events, and (f) is the difference (d) - (e). The moisture fluxes across the meridional wall and zonal wall are found to be statistically significant at a $99 \%$ level based on Student's t-test. 
essentially explains the relationship between the above moisture flux and TT gradient variation.

Because of the above established linkage between the TT gradient and moisture transport, we speculate that the former may have different impacts on the monsoon precipitation over East Asia during the El Niño and La Niña periods. To investigate this, we regress the wind at $200 \mathrm{mb}$, wind vector shear (200 - $850 \mathrm{mb}$ ), and moisture flux onto the TT gradient during the DJF El Niño and La Niña periods, respectively, using the traditional regression analysis technique. As shown in Fig. 6, over East Asia, the regressed winds essentially appear as a cyclone during El Niño years and an anticyclone during La Niña years, and this is in agreement with the aforementioned large scale circulation anomalies (refer Fig. 4). On the moisture flux maps, remarkably, the moisture is transported from the East China Sea toward mainland China during the El Niño years, while during the La Niña years, the flux is rather weak, and directs northeastward. This implies that the TT gradient may have a much larger impact on the precipitation over China during El Niño years than during La Niña years.

Since moisture is a basic element in the monsoon system, we speculate that the TT gradient will play a corresponding role in the precipitation variation during the wintertime El Niño and La Niña periods. To see this, we first take a look at the composite precipitation anomaly (in $\mathrm{mm} \mathrm{day}^{-1}$ ) patterns for El Niño and La Niña years. They are shown in Figs. 7a and b, and their difference in Fig. 7c. Obviously, the difference in precipitation looks well in agreement with the indicated large-scale dynamical process (Figs. 4 and 6).

We further apply the "composite causality analysis", which was briefly introduced in section 2 and detailed in Appendix A, to examine the direct relationship between the TT gradient and precipitation during the two different climate modal periods (El Niño and La Niña) which have been linked to many natural hazards on earth. By using a time window of size $\mathrm{M}$, we in the end obtain a series of causality. Using our previous criterion for composite analysis we are then able to select out the causalities for the El Niño and La Niña events. We have tried different time window sizes, such as $31,41,51$ days, etc., and the resulting causal patterns are similar. (Note one cannot choose two big a time window such as half a year; otherwise the El Niño and La Niña events would be mixed.) The results are shown in Fig. 8. As can be seen, during El Niño years, the TT gradient is causal to the precipitation all over China, but during La Niña years, it is only significantly causal to that over Inner Mongolia, Jiangsu-Zhejiang, and Northeast China. This is generally consistent with the previous regression analysis, particularly the regressed analysis of moisture flux (Fig. 6), which is rather weak over China, and most importantly, directing seaward, during the La Niña years. But, of course, much more details are revealed here in the causality analysis.

It is noteworthy to mention that the causalities obtained here are asymmetric in direction; that is to say, they are from the TT gradient to precipitation, which has nothing to do with that from the other way around. This is in contrast to the traditional tools such as correlation analysis, which is symmetric and hence cannot tell which causes which. Besides, not only have we been able to determine the directions of causality, but also the magnitudes. In the El Niño years, the impact of TT gradient is most pronounced over Tibet Plateau, Yunnan, and over a southeast-northwest belt, from Zhejiang-Jiangsu-Shandong to Shanxi, to Xinjiang. Second to these regions are Inner Mongolia and the Northeast, while over the Guangdong-Sichuan belt the impact is weak. This spatial distribution implies that the TT gradient index can be used as a factor for the prediction of the precipitation over the corresponding regions (i.e., the regions with large causality), which we will be elaborating in future studies. In the La Niña years, overall the impact of TT gradient is rather weak, except over inner Mongolia. Besides, over Jiangsu-Shanghai-Zhejiang the impact is also significant, though rather weak by comparison. This remarkable result from another aspect distinguishes the role of TT gradient on the East Asian precipitation in the two ENSO phases, i.e., El Niño and La Niña.

\section{CONCLUDING REMARKS}

The National Center for Environmental Prediction (NCEP) - DOE AMIP 2 reanalysis daily air temperature datasets for the boreal winters (DJF) of 1982 to 2014 were utilized to study the TT variation (the layer-averaged TT between 1000 - $400 \mathrm{mb}$ ) over East Asia and its impact on the local precipitation during different ENSO phases. This analysis reveals distinctly different patterns of TT variability over the two regions in Fig. 2, namely, regions I and II, during El Niño and La Niña events. We subtracted the TT averaged over region I from that over region II, which we refer to as TT gradient, and form a time series. It is found that the TT gradient during El Niño events is significantly weaker than that during La Niña events. This, as implied by the thermal wind relation, implies distinctly different circulation patterns during the two ENSO phases, which are characterized by an anticyclonic (resp. cyclonic) circulation over region I (resp. region II) during the El Niño (resp. La Niña) events. This forms the dynamical reason behind the moisture transport, and hence controls the difference in precipitation pattern over East Asia, which is further substantiated with the traditional regression analysis and a newly developed technique for causality inference from time series.

Acknowledgements We are grateful to the editor and two anonymous reviewers for their valuable comments and suggestions, which helped to improve the manuscript. Thanks are due to NOAA, APHRODITE's team, NCEP-DOE AMIP 2 Reanalysis Version 2 team for providing the respective 

(a)
DJF ELNINO
(d)
DJF LANINA
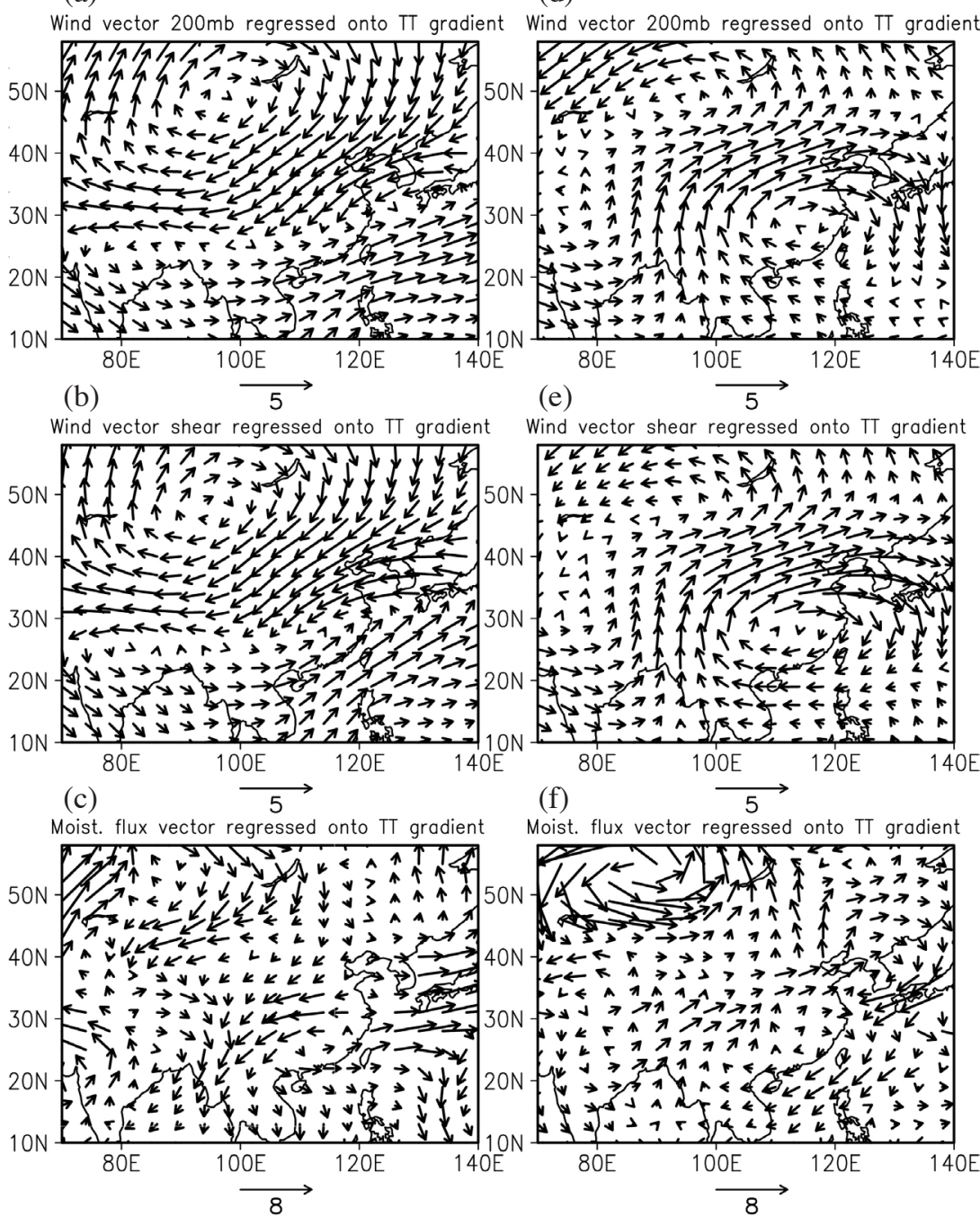

Moist. flux vector regressed onto $T T$ gradient

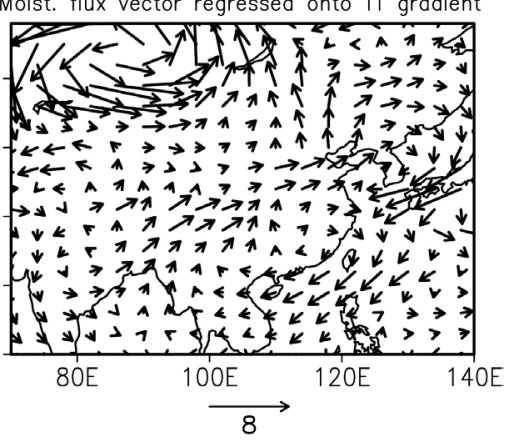

Fig. 6. (a) Wind vector at $200 \mathrm{mb}$, (b) wind vector shear (200 - $850 \mathrm{mb}$ ), and (c) moisture flux vector regressed onto the TT gradient during DJF El Niño events. (d), (e), and (f) are like (a), (b), and (c) but for DJF La Niña events. Regression coefficients are statistically significant at a 99\% level based on student's t-test.
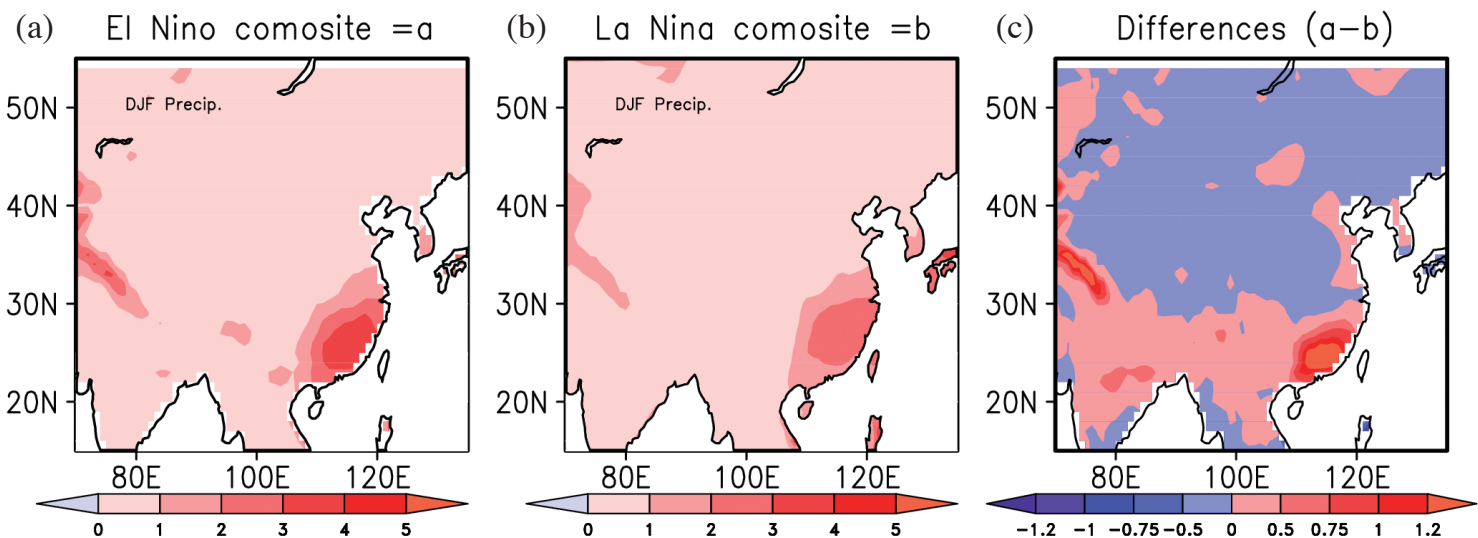

Fig. 7. DJF precipitation (a) El Niño composite (b) La Niña composite (c) difference (a) - (b). The unit of precipitation is mm day ${ }^{-1}$. 


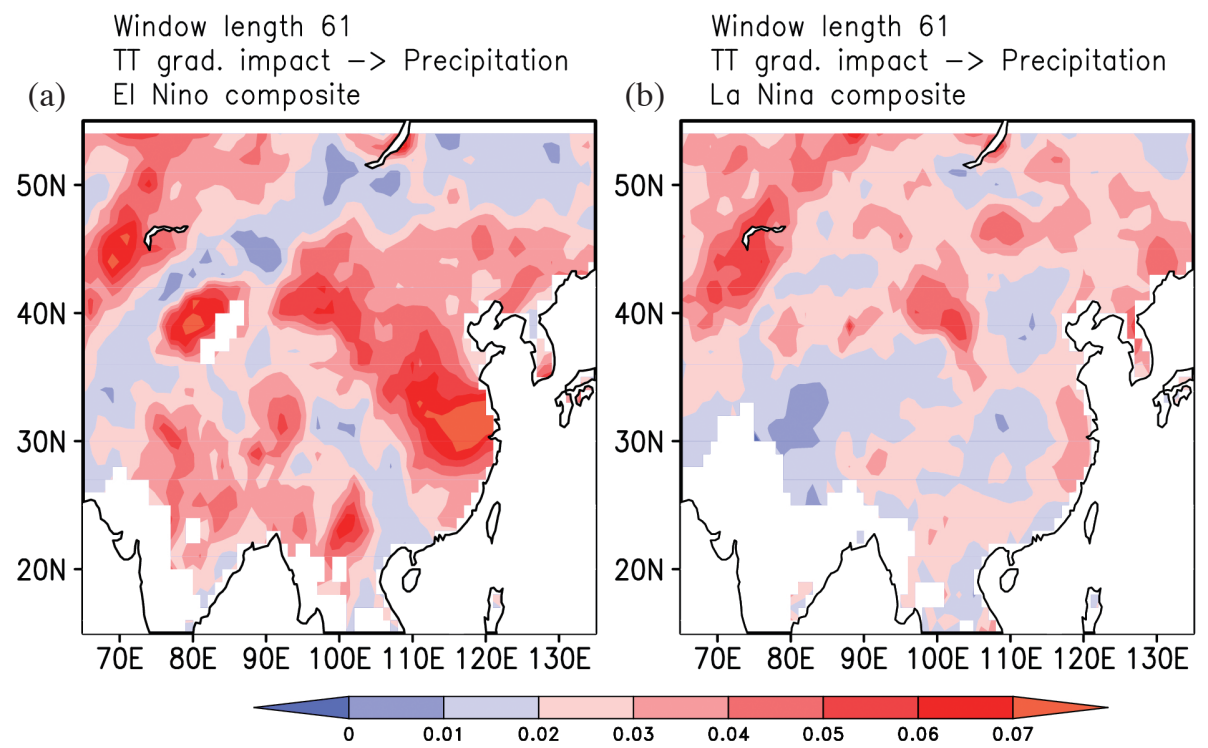

Fig. 8. The causality (information flow in nats day ${ }^{-1}$ ) from the TT gradient to precipitation for a time window size of 61 days: (a) El Niño composite; (b) La Niña composite. Nat is the unit for information and entropy, which has the form of $\int \rho \log \rho$ ( $\rho$ is the probability density function). The logarithm uses a base $e$.

datasets. The figures were prepared with GrADS. This research was supported by the Jiangsu Provincial Government through the "2015 Jiangsu Program for Innovation Research and Entrepreneurship Groups" and the Jiangsu Chair Professorship, the State Oceanic Administration through the National Program on Global Change and Air-Sea Interaction (GASI-IPOVAI-06) and the Key Laboratory of Meteorological Disaster of Ministry of Education (KLME1603).

\section{REFERENCES}

Emanuel, K., 2010: Tropical Cyclone Activity Downscaled from NOAA-CIRES Reanalysis, 1908-1958. J. Adv. Model. Earth Syst., 2, doi: 10.3894/JAMES.2010.2.1. [Link]

Gill, A. E., 1980: Some simple solutions for heat-induced tropical circulation. Q. J. R. Meteorol. Soc., 106, 447462, doi: 10.1002/qj.49710644905. [Link]

Ha, K.-J., K.-Y. Heo, S.-S. Lee, K.-S. Yun, and J.-G. Jhun, 2012: Variability in the East Asian monsoon: A review. Meteorol. Appl., 19, 200-215, doi: 10.1002/met.1320. [Link]

He, J., J. Ju, Z. Wen, J. Lü, and Q. Jin, 2007: A review of recent advances in research on Asian monsoon in China. Adv. Atmos. Sci., 24, 972-992, doi: 10.1007/s00376007-0972-2. [Link]

Holton, J. R., 2004: An Introduction to Dynamic Meteorology, International Geophysics, Vol. 88, Academic Press, Burlington, Mass, 535 pp.

Huang, R., J. Chen, and G. Huang, 2007: Characteristics and variations of the East Asian monsoon system and its impacts on climate disasters in China. Adv. Atmos. Sci., 24, 993-1023, doi: 10.1007/s00376-007-0993-x. [Link]

Jhun, J.-G. and E.-J. Lee, 2004: A new East Asian winter monsoon index and associated characteristics of the winter monsoon. J. Climate, 17, 711-726, doi: 10.11 75/1520-0442(2004)017<0711:ANEAWM>2.0.CO;2. [Link]

Kanamitsu, M., W. Ebisuzaki, J. Woollen, S. Yang, J. J. Hnilo, M. Fiorino, and G. L. Potter, 2002: NCEPDOE AMIP-II reanalysis (R-2). Bull. Amer. Meteorol. Soc., 83, 1631-1644, doi: 10.1175/BAMS-83-11-1631. [Link]

Liang, X. S., 2014: Unraveling the cause-effect relation between time series. Phys. Rev. E, 90, doi: 10.1103/PhysRevE.90.052150. [Link]

Liang, X. S., 2015: Normalizing the causality between time series. Phys. Rev. E, 92, doi: 10.1103/PhysRevE.92.022126. [Link]

Liang, X. S., 2016: Information flow and causality as rigorous notionsab initio. Phys. Rev. E, 94, doi: 10.1103/ PhysRevE.94.052201. [Link]

Liang, X. S., 2018: Causation and information flow with respect to relative entropy. Chaos, 28, doi: 10.1063/1.5010253. [Link]

Nakamura, H., 1992: Midwinter suppression of baroclinic wave activity in the Pacific. J. Atmos. Sci., 49, 1629 1642, doi: 10.1175/1520-0469(1992)049<1629:MSO $\mathrm{BWA}>2.0 . \mathrm{CO} ; 2$. [Link]

Neelin, J. D., 2011: Climate Change and Climate Modeling, Cambridge University Press, Cambridge, UK, 282 pp. 
Palmén, E., 1948: On the distribution of temperature and wind in the upper westerlies. J. Meteor., 5, 20-27, doi: 10.1175/1520-0469(1948)005<0020:OTDOTA > 2.0.C $\mathrm{O} ; 2$. [Link]

Ratnam, J. V., S. K. Behera, Y. Masumoto, and T. Yamagata, 2014: Remote effects of El Niño and Modoki events on the austral summer precipitation of Southern Africa. J. Climate, 27, 3802-3815, doi: 10.1175/JCLID-13-00431.1. [Link]

Reynolds, R. W., N. A. Rayner, T. M. Smith, D. C. Stokes, and W. Wang, 2002: An improved in situ and satellite SST analysis for climate. J. Climate, 15, 1609-1625, doi: 10.1175/1520-0442(2002)015<1609:aiisas >2.0.c o;2. [Link]

Rodwell, M. J. and B. J. Hoskins, 1996: Monsoons and the dynamics of deserts. Q. J. R. Meteorol. Soc., 122, 1385-1404, doi: 10.1002/qj.49712253408. [Link]

Ruti, P. M., V. Lucarini, A. Dell'Aquila, S. Calmanti, and A. Speranza, 2006: Does the subtropical jet catalyze the midlatitude atmospheric regimes? Geophys. Res. Lett., 33, L06814, doi: 10.1029/2005GL024620. [Link]

Schneider, E. K. and R. S. Lindzen, 1977: Axially symmetric steady-state models of the basic state for instability and climate studies. Part I. Linearized calculations. $J$. Atmos. Sci., 34, 263-279, doi: 10.1175/1520-0469(197 7) $034<0263$ :asssmo $>2.0 . c 0 ; 2$. [Link]

Thompson, D. W. J. and J. M. Wallace, 1998: The Arctic oscillation signature in the wintertime geopotential height and temperature fields. Geophys. Res. Lett., 25, 1297-1300, doi: 10.1029/98GL00950. [Link]

Vaid, B. H. and X. S. Liang, 2015: Tropospheric temperature gradient and its relation to the South and East Asian precipitation variability. Meteorol. Atmos. Phys., 127, 579-585, doi: 10.1007/s00703-015-0385-1. [Link]

Vaid, B.H. and X. S. Liang, 2018: An Abrupt Change in Tropospheric Temperature Gradient and Moisture Transport Over East Asia in the Late 1990s. Atmos.-Ocean, 56, 268-276, doi: 10.1080/07055900.2018.1429381. [Link]

Vecchi, G. A., S. Fueglistaler, I. M. Held, T. R. Knutson, and M. Zhao, 2013: Impacts of Atmospheric Temperature Trends on Tropical Cyclone Activity. J. Climate, 26, 3877-3891, doi: 10.1175/JCLI-D-12-00503.1. [Link]

Wang, L., R. Huang, L. Gu, W. Chen, and L. Kang, 2009: Interdecadal variations of the East Asian winter monsoon and their association with quasi-stationary planetary wave activity. J. Climate, 22, 4860-4872, doi: 10.1175/2009JCLI2973.1. [Link]

Webster, P. J., 1987: The elementary monsoon. In: Fein, J. S. and P. L. Stephens (Eds.), Monsoons, John Wiley, Hoboken, New York, 3-32.

Webster, P. J., V. O. Magaña, T. N. Palmer, J. Shukla, R. A. Tomas, M. Yanai, and T. Yasunari, 1998: Monsoons: Processes, predictability, and the prospects for prediction. J. Geophys. Res., 103, 14451-14510, doi: 10.1029/97JC02719. [Link]

Wei, M.-Y., 1987: A new formulation of the exchange of mass and trace constituents between the stratosphere and troposphere. J. Atmos. Sci., 44, 3079-3086, doi: 1 0.1175/1520-0469(1987)044<3079: anfote>2.0.co;2. [Link]

Wu, B., 2005: Weakening of Indian summer monsoon in recent decades. Adv. Atmos. Sci., 22, 21-29, doi: 10.1007/ BF02930866. [Link]

Wu, R., Z.-Z. Hu, and B. P. Kirtman, 2003: Evolution of ENSO-related rainfall anomalies in East Asia. J. Climate, 16, 3742-3758, doi: 10.1175/1520-0442(2003)0 16<3742:EOERAI >2.0.CO;2. [Link]

Yatagai, A., K. Kamiguchi, O. Arakawa, A. Hamada, N. Yasutomi, and A. Kitoh, 2012: APHRODITE: Constructing a Long-term Daily Gridded Precipitation dataset for Asia based on a Dense Network of Rain Gauges. Bull. Amer. Meteorol. Soc., 93, 1401-1415, doi: 10.1175/BAMS-D-11-00122.1. [Link]

Zhou, L. T. and R. Wu, 2010: Respective impacts of the East Asian winter monsoon and ENSO on winter rainfall in China. J. Geophys. Res., 115, D02107, doi: 10.1029/2009JD012502. [Link]

Zhou, W., J. C. L. Chan, W. Chen, J. Ling, J. G. Pinto, and Y. Shao, 2009: Synoptic-scale controls of persistent low temperature and icy weather over southern China in January 2008. Mon. Weather Rev., 137, 3978-3991, doi: 10.1175/2009MWR2952.1. [Link]

\section{APPENDIX A. CAUSALITY BETWEEN TIME SERIES AND COMPOSITE CAUSALITY ANALYSIS}

Causality analysis is lying at the heart of science. During the past few years, Liang (2014) and Liang (2016) established that the causality between a couple of series, say, $X_{1}$ and $X_{2}$, can be rigorously derived from first principles. [A one-page review of the theory is referred to section 2 of Liang (2018).] Moreover, the resulting formula is very concise in form and very easy to use. In the linear limit, the maximum likelihood estimator (MLE) of the causality from $X_{2}$ to $X_{1}$ (units: nats per unit time) is:

$T_{2 \rightarrow 1}=\frac{C_{11} C_{12} C_{2, d 1}-C_{12}^{2} C_{1, d 1}}{C_{11}^{2} C_{22}-C_{11} C_{12}^{2}}$

where $C_{i j}$ is the sample covariance between the time series $X_{i}$ and $X_{j}(i, j=1,2)$, and $C_{i, d j}$ the covariance between $X_{i}$ and the series

$\dot{X}_{j}=\frac{X_{j}(t+k \Delta t)-X_{j}(t)}{k \Delta t}$ 
i.e., a series derived from $X_{j}(t)$ using the Euler forward differencing scheme, with $\Delta t$ being the time stepsize and $k$ $\geq 1$ some integer. [Note this is the MLE of the rigorously derived causality under an assumption of linearity; for the original formula, see Liang (2016).] Ideally, when $T_{2 \rightarrow 1}$ is nonzero, then $X_{2}$ is causal to $X_{1}$; otherwise it is not causal, but practically a statistical significance test should be performed (Liang 2015) to assess whether it is distinctly different from zero. In the present study, the computed causality is at a 95\% confidence level. An immediate corollary of the above rigorously derived formula is that causation implies correlation, but correlation does not imply causation, resolving the long-standing philosophical debate over causation versus correlation. For details about the derivation and applications (in climate science and financial economics, among others), see Liang (2014, 2015, 2016), among many others.

The Eq. (A1) is very easy to implement, but it cannot be directly applied in this present study. In order to examine the measurable impact of the TT variation on the precipitation over East Asia during El Niño and La Niña, we have selected out of the overall time steps only those relevant to the two events; that is to say, the so-obtained time series are actually rather irregularly formed, with time steps ranging from a day to more than a year (if there is no El Niño nor La Niña in the year). Besides, only wintertime data are consid- ered. All these lead to broken, irregular, and very coarsely resolved time series, which cannot be used for the computation of the covariances in Eq. (A1).

Fortunately in this case we have all the complete time series available. The above broken and irregular time series arise from the composite analysis as performed. We hence can have the causalities computed for all the time steps, and then perform composite analyses for the causalities during the El Niño and La Niña events, respectively. In this way, the aforementioned difficulty is circumvented. We call this technique composite causality analysis.

To perform a composite causality analysis, we first need to compute the causalities at all the time steps. That is to say, to form a "field of causality". This is fulfilled through running time window causality analysis. For time series of length $\mathrm{N}$ (with time steps $1,2,3, \ldots, \mathrm{N}$ ), suppose we consider a time window of length $\mathrm{M}$, with $\mathrm{M}<\mathrm{N}$. We first perform the analysis for the sub-series on steps $1,2, \ldots, M$, then slide the window rightward by 1 and do the analysis for the sub-series on steps $2,3, \ldots, M+1$, and so forth. In the end we will obtain a series of causality on time steps centered at these sliding windows (no value at the beginning $\mathrm{M} / 2$ steps and the last $\mathrm{M} / 2$ steps). Once this is done, these causalities can be composited based on some preset criterion (see the text). In this way the composite causalities for the El Niño and La Niña events are obtained. 